\title{
Rheological Properties of Self-Compacting Concrete with 3- Dimensional Fibres
}

\author{
J. Ramli*, B. Nagaratnam, K. Poologanathan, W. M. Cheung, T. Suntharalingam, A. Richardson \\ Department of Mechanical and Construction Engineering \\ Northumbria University, Newcastle upon Tyne, NE1 8ST, UK \\ Jeffri.Ramli@northumbria.ac.uk (*corresponding author); Brabha.Nagaratnam@northumbria.ac.uk; \\ Keerthan.Poologanathan@northumbria.ac.uk; Wai.M.Cheung@northumbria.ac.uk \\ Thadshajini.Suntharalingham@northumbria.ac.uk; Alan.Richardson@northumbria.ac.uk
}

\begin{abstract}
This study investigates the effect of 3-dimensional (3D) fibres on the rheological properties of self-compacting concrete (SCC) using three different fibre volume fractions (1\%,2\% and 3\%). Two different sizes of 3D fibres with perimeters of $115 \mathrm{~mm}$ and $220 \mathrm{~mm}$ were considered. Rheological properties were determined through slump flow, J-ring, V-funnel and sieve segregation tests. The test results reveal that the addition of 3D fibres decreases the workability of the SCC. 3D fibres with a perimeter of $220 \mathrm{~mm}$ have a more adverse effect on the rheological properties of SCC than 3D fibres with a perimeter $115 \mathrm{~mm}$. The balling effect occurred when $2 \%$ and $3 \%$ fibre volume fractions of 3D fibres with a perimeter of $220 \mathrm{~mm}$ were added to the mixture, compromising the workability of SCC.
\end{abstract}

Keywords: Self-compacting concrete, 3-dimensional fibres, Rheological properties, Workability.

\section{Introduction}

Self-compacting concrete (SCC) is a highly workable cementitious material that can flow under its own weight, thus eliminating any need for compaction and complexity of the formwork, especially in the presence of congested reinforcement $[1,2]$. SCC in its hardened state has the same engineering properties and durability as conventional vibrated concrete (CVC) [3]. SCC is more economical than CVC by reducing the labour costs, vibrating equipment and by rapid casting [4]. The composition of SCC requires the use of less coarse aggregate and a smaller water-to-cement ratio (w/c), while a high range superplasticiser (SP) and increased volume paste are added [5]. The concept of SCC was first introduced in Japan in 1988 to achieve durable concrete structures by improving quality in the construction process and was in response to the reduction in the numbers of skilled workers available in the industry [6].

The addition of fibres in SCC will extend its benefits as they help to bridge cracks and delay their propagation and thus improve the mechanical properties of hardened concrete [7]. Therefore, the use of fibres may extend the possible fields of application of SCC. The major advantages of incorporating fibres in SCC are the elimination the need for the conventional methods of compaction to consolidate the concrete [8] and the enhancement of the stability of the SCC matrix [9]. However, fibres are also known to reduce the workability and flow characteristics of fresh SCC [7-9]. Moreover, it is well understood that the reduction of workability due to the addition of fibres is mainly dependent on the type, geometry, amount of fibres used, and dispersion in the SCC [7,8]. The content of fibres that can be used while the mix is still workable depends entirely on the mixture composition and the type of fibres [7].

Over the years, numerous researches have been conducted to enhance the understanding of SCC incorporating various types of fibres (steel and polymer fibres), which are predominantly 2D fibres. To the authors' knowledge, no previous research has been reported on the use of 3D fibres in SCC. Therefore, this paper aims to investigate the influence of 3D fibres on the workability of SCC. Combining both 3D fibres and SCC into one type of cementitious composite would create new possibilities in structural engineering. 


\section{Experimental Program}

\subsection{Materials}

\subsubsection{Cement}

In this study, rapid hardening Portland cement (RHPC) (CEM $152.5 \mathrm{R}$ ) with a specific gravity of $3.12 \mathrm{~g} / \mathrm{cm}^{3}$ and Blaine fineness of $455 \mathrm{~m}^{2} / \mathrm{kg}$ were used. The physical properties and chemical compositions of the cement are presented in Table 1 and Table 2.

Table 1: Physical properties of RHPC.

\begin{tabular}{lll}
\hline Test & Values obtained & Requirement of BS EN 197-1:2011 [10] \\
\hline Initial setting time (min) & 155 & 40 (minimum) \\
Compressive strength (MPa) & & \\
2 days & 36.5 & 28 \\
7 days & 52 & - \\
28 days & 62 & 50 \\
Soundness $(\mathrm{mm})$ & 1 & 10 (maximum) \\
$\quad$ Blaine fineness $\left(\mathrm{m}^{2} / \mathrm{kg}\right)$ & 455 & - \\
$\quad$ Specific gravity & 3.12 & - \\
\hline
\end{tabular}

Table 2: Chemical compositions of RHPC.

\begin{tabular}{lll}
\hline Compound & Values obtained (\%) & Requirement of BS EN 196:2011 [10] \\
\hline $\mathrm{SiO}_{2}$ & 19.58 & - \\
$\mathrm{Al}_{2} \mathrm{O}_{3}$ & 4.56 & - \\
$\mathrm{Fe}_{2} \mathrm{O}_{3}$ & 2.82 & - \\
$\mathrm{CaO}$ & 63.36 & - \\
$\mathrm{MgO}$ & 1.10 & - \\
$\mathrm{SO}_{3}$ & 3.24 & $\leq 4.0 \%$ \\
$\mathrm{~K}_{2} \mathrm{O}$ & 0.70 & - \\
$\mathrm{Na}_{2} \mathrm{O}$ & 0.22 & - \\
$\mathrm{Cl}$ & 0.05 & $\leq 0.10 \%$ \\
Loss on ignition & 2.61 & $\leq 5.0 \%$ \\
\hline
\end{tabular}

\subsubsection{Coarse and Fine Aggregates}

The coarse aggregate was limestone gravel (Fig. 1(a)) with a nominal maximum size of $14 \mathrm{~mm}$ and the fine aggregate used was natural river sand (Fig. 1(b)) and coarse sand from crushed igneous rock (Fig. 1(c)), both with a maximum size of $4 \mathrm{~mm}$. All coarse and fine aggregates had a specific of $2.60 \mathrm{~g} / \mathrm{cm}^{3}$. Fig. 2 shows the grading curve for fine and coarse aggregates.

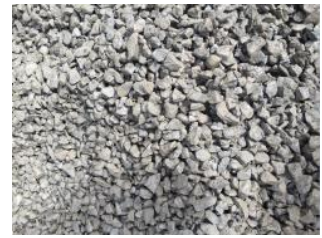

Fig. 1(a): Limestone gravel.

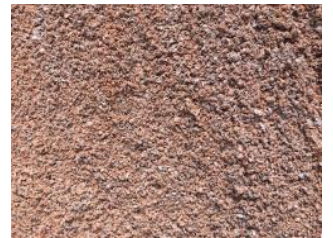

Fig. 1(b): Coarse sand.

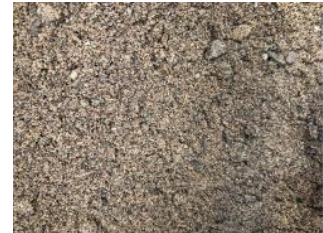

Fig. 1(c): Natural river sand. 


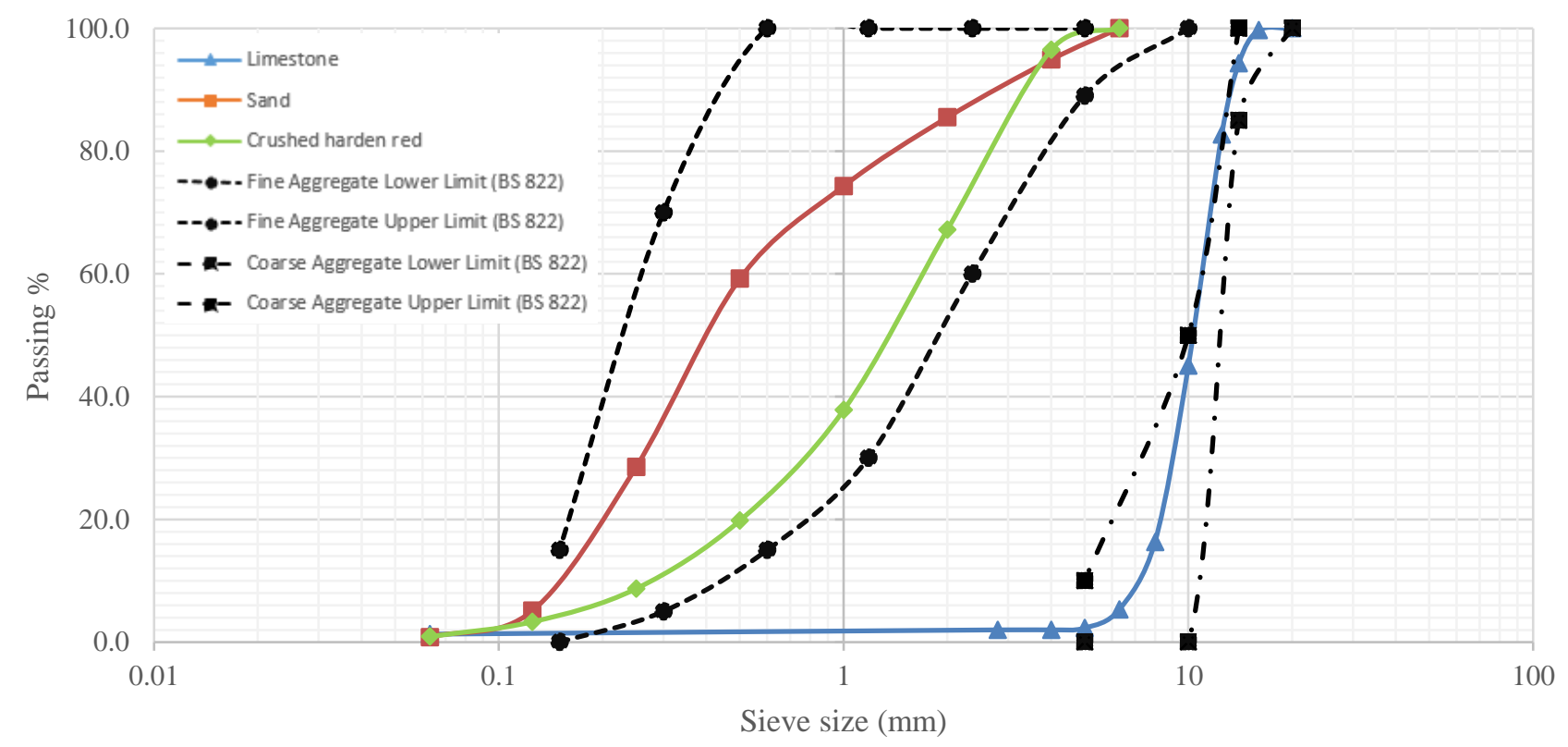

Fig. 2: Sieve analysis of fine and coarse aggregate.

\subsubsection{Superplasticiser}

MasterMatrix 233, a polycarboxylic ether polymer superplasticiser (SP) with a specific gravity of $1.06 \mathrm{~g} / \mathrm{cm}^{3}$, was employed to achieve the desired workability in all concrete mixtures. The properties of superplasticiser are given in Table 3.

Table 3: Properties of superplasticiser.

\begin{tabular}{ll}
\hline Properties & Superplasticiser \\
\hline Name & MasterMatrix 233 \\
Manufacturer & BASF \\
Appearance & Yellow liquid \\
Specific gravity & 1.06 \\
Chemical description & Polycarboxylic ether type polymer \\
Recommended dosage & By volume -0.28 to 1.13 litres per $100 \mathrm{~kg}$ of cement \\
& By mass -0.30 to $1.20 \mathrm{~kg}$ per $100 \mathrm{~kg}$ of cement \\
\hline
\end{tabular}

\subsubsection{D Fibres}

In this study, two different sizes of closed-loop 3D fibres were considered. Fig. 3 shows the different sizes of closedloop 3D fibres used in the study. 3D fibres with a perimeter of $115 \mathrm{~mm}$ at $28.75 \mathrm{~mm}$ wide on each side (Fig. 3(a)) was noted as S3D, while 3D fibres with a perimeter with $220 \mathrm{~mm}$ at $55 \mathrm{~mm}$ wide on each side (Fig. 3(b)) was noted as L3D. The 3D fibres were manufactured using copper-coated mild steel wire with a $1 \mathrm{~mm}$ thickness. The wire has a tensile strength of 1498 $\mathrm{MPa}$ and a modulus of elasticity of $200 \mathrm{GPa}$. It was cut and bent into a triangular shape, as suggested by Richardson \& Heather (2013) [11]. A lead-free soldering iron was used to close the gap between each 3D fibre. 


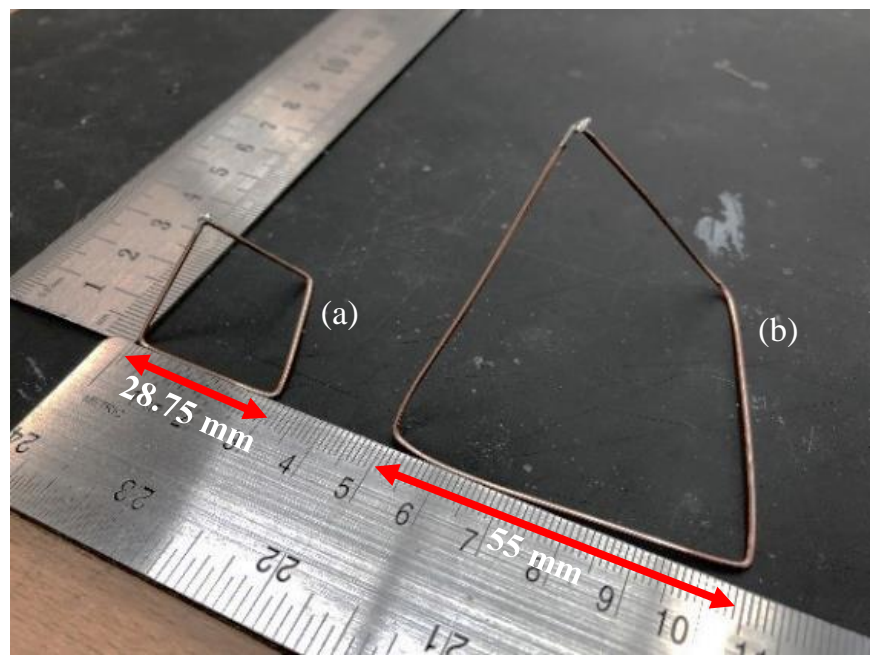

Fig. 3: Different sizes of 3D fibres used; (a) S3D: $115 \mathrm{~mm}$ perimeter (b) L3D: $220 \mathrm{~mm}$ perimeter.

\subsubsection{Mixing Water}

Ordinary portable water was used in this study for all concrete mixes.

\subsection{Mix Design}

SCC mixtures were designed having a constant water to cement (w/c) ratio of 0.39 and cement content of $480 \mathrm{~kg} / \mathrm{m}^{3}$. Seven mixes were prepared; no fibres were mixed in SCC, while the remaining six mixes were added with 3D fibres. Three fibre volume fractions of $1 \%, 2 \%$ and $3 \%$ by mass of cement were considered. The detailed mix proportions for all concrete mixtures are presented in Table 4.

Table 4: Mix proportions for self-compacting concrete.

\begin{tabular}{lcccccccc}
\hline Mix ID & $\begin{array}{c}\text { Cement } \\
\left(\mathbf{k g} / \mathbf{m}^{\mathbf{3}}\right)\end{array}$ & $\begin{array}{c}\text { Limestone } \\
\left(\mathbf{k g} / \mathbf{m}^{\mathbf{3}}\right)\end{array}$ & $\begin{array}{c}\text { Fine sand } \\
\left(\mathbf{k g} / \mathbf{m}^{\mathbf{3}}\right)\end{array}$ & $\begin{array}{c}\text { Course sand } \\
\left(\mathbf{k g} / \mathbf{m}^{\mathbf{3}}\right)\end{array}$ & $\begin{array}{c}\text { Water } \\
\left(\mathbf{k g} / \mathbf{m}^{\mathbf{3}}\right)\end{array}$ & $\begin{array}{c}\mathbf{S P} \\
\left(\mathbf{k g} / \mathbf{m}^{\mathbf{3}}\right)\end{array}$ & $\begin{array}{c}\text { S3D } \\
(\boldsymbol{\%})\end{array}$ & $\begin{array}{c}\mathbf{L 3 D} \\
(\boldsymbol{\%})\end{array}$ \\
\hline SCC & 480 & 795 & 668 & 265 & 187 & 3.95 & 0 & 0 \\
SCC-S3D1 & 480 & 795 & 668 & 265 & 187 & 3.95 & 1.00 & 0 \\
SCC-S3D2 & 480 & 795 & 668 & 265 & 187 & 3.95 & 2.00 & 0 \\
SCC-S3D3 & 480 & 795 & 668 & 265 & 187 & 3.95 & 3.00 & 0 \\
SCC-L3D1 & 480 & 795 & 668 & 265 & 187 & 3.95 & 0 & 1.00 \\
SCC-L3D2 & 480 & 795 & 668 & 265 & 187 & 3.95 & 0 & 2.00 \\
SCC-L3D3 & 480 & 795 & 668 & 265 & 187 & 3.95 & 0 & 3.00 \\
\hline
\end{tabular}

\subsection{Mixing Procedure}

The mixing was carried out in a 130-litre capacity free-fall type mixer with tilting drum and two rotating blades. The mixer was pre-damped with water before mixing. The total mixing duration for each batch was kept as low as possible (approximately 10 minutes) to prevent the fresh concrete mix from segregation. Initially, coarse and fine aggregate were dry mixed for a minute. The cement was then added and mixed for another minute. $70 \%$ of the water was then gradually added to the mix and the mixing was continued for further two minutes. The remaining $30 \%$ of the water mixed with superplasticiser was added and the mixing was continued for two minutes. Finally, the mixing was halted for two minutes and the mixing was continued for another two minutes before performing workability tests. 


\subsection{Test Methods}

The rheological properties of the SCC mixes were evaluated as recommended by the EFNARC [3,12] committee to test to test their filling ability, passing ability, and segregation resistance. Filling ability was tested using slump flow and Vfunnel tests while J-ring test was used to measure passing ability. Segregation resistance was measured by sieve segregation segregation test. A visual stability index (VSI) was also given for each mix, in accordance with ASTM C1611 (Standard Test Test Method for Slump Flow of Self-Consolidating Concrete) [12], that corresponds to nature of the spread during a slump flow test.

\section{Results and Discussions}

In order to assess the workability of SCC with and without fibres slump flow (SF) with $\mathrm{T}_{500}$ time, V-funnel time $\left(\mathrm{V}_{\mathrm{t}}\right), \mathrm{J}$ ring slump flow $\left(\mathrm{SF}_{\mathrm{J}}\right)$ with $\mathrm{T}_{500 \mathrm{~J}}$ time and step height $(\mathrm{PJ})$, sieve segregation and visual stability index (VSI) tests were conducted. The results of rheological properties of all SCC mixes are shown in Table 5. The results

Table 5: Workability test results.

\begin{tabular}{|c|c|c|c|c|c|c|c|c|c|}
\hline \multirow[b]{2}{*}{$\begin{array}{c}\text { Key } \\
\text { Properties }\end{array}$} & \multirow{2}{*}{\multicolumn{2}{|c|}{ Fresh Property Tests }} & \multicolumn{7}{|c|}{ Mix ID } \\
\hline & & & SCC & $\begin{array}{l}\text { SCC- } \\
\text { S3D1 }\end{array}$ & $\begin{array}{l}\text { SCC- } \\
\text { S3D2 } \\
\end{array}$ & \multirow{2}{*}{$\begin{array}{c}\begin{array}{c}\text { SCC- } \\
\text { S3D3 }\end{array} \\
7.21\end{array}$} & \multirow{2}{*}{\begin{tabular}{|c|} 
SCC- \\
L3D1 \\
7.18 \\
\end{tabular}} & \multirow{2}{*}{$\begin{array}{c}\text { SCC- } \\
\text { L3D2 } \\
7.66 \\
\end{array}$} & \multirow{2}{*}{$\begin{array}{c}\begin{array}{c}\text { SCC- } \\
\text { L3D3 }\end{array} \\
8.12 \\
\end{array}$} \\
\hline \multirow{3}{*}{$\begin{array}{l}\text { Filling } \\
\text { Ability }\end{array}$} & \multirow{2}{*}{$\begin{array}{l}\text { Slump } \\
\text { Flow }\end{array}$} & $\mathrm{T}_{500}(\mathrm{~s})$ & 7.10 & 7.11 & 7.17 & & & & \\
\hline & & $\mathrm{SF}(\mathrm{mm})$ & 650 & 570 & 560 & 555 & 594 & 571 & 550 \\
\hline & V-Funnel & $\mathrm{V}_{\mathrm{t}}(\mathrm{s})$ & 11.67 & 14.83 & 14.97 & 15.18 & 14.56 & Blocking & Blocking \\
\hline \multirow{3}{*}{$\begin{array}{l}\text { Passing } \\
\text { Ability }\end{array}$} & \multirow{3}{*}{ J-Ring } & $\mathrm{SF}_{\mathrm{J}}(\mathrm{mm})$ & 595 & 556 & 551 & 543 & 581 & 565 & 540 \\
\hline & & $\mathrm{T}_{500 \mathrm{~J}}(\mathrm{~s})$ & 7.72 & 8.14 & 8.19 & 8.25 & 7.83 & 8.04 & 8.46 \\
\hline & & $\mathrm{PJ}(\mathrm{mm})$ & 15.0 & 27.5 & 30.3 & 30.8 & 16.5 & 39.5 & 103.5 \\
\hline \multirow{2}{*}{$\begin{array}{l}\text { Segregation } \\
\text { Resistance }\end{array}$} & VSI & Index $(0-3)$ & 0 & 0 & 0 & 1 & 0 & 1 & 1 \\
\hline & $\begin{array}{l}\text { Sieve } \\
\text { Stability }\end{array}$ & $\mathrm{SR}(\%)$ & 2.9 & 2.6 & 2.2 & 1.8 & 4.0 & 3.6 & 3.1 \\
\hline
\end{tabular}

\subsection{Slump Flow and $T_{500}$ Flow Time}

Fig. 4 shows the slump flow and $\mathrm{T}_{500}$ time for different $\mathrm{SCC}$ mixtures. SCC has a slump flow (SF) of $650 \mathrm{~mm}$ and $\mathrm{SF}$ was significantly reduced when the 3D fibres were added in SCC. Addition of 1\% of S3D fibres reduced the slump by 80 $\mathrm{mm}$, while $1 \%$ of L3D fibres reduced the slump by $56 \mathrm{~mm}$. When $2 \%$ of S3D and L3D were added, the slump spreads were further reduced by $90 \mathrm{~mm}$ and $79 \mathrm{~mm}$, respectively. A further reduction of slump spreads by $95 \mathrm{~mm}$ and $101 \mathrm{~mm}$ with the addition 3\% of S3D and L3D, respectively. All the SCC mixtures have a slump flow that was within the range of 550 to 650 mm prescribed by EFNARC [7] and fall under the SF1 category.

However, the addition of $2 \%$ and $3 \%$ of L3D in the SCC caused the fibres to clump together, as illustrated in Fig. 5. The common term used for this phenomenon is balling effect [14]. It was found that the bond between the soldering iron and the gap between some of the fibres snapped due to the force exerted by the vigorous mixing achieved by the blades of pan mixer. As a result, the fibres within the SCC mix entangled with each other and clumped together. Therefore, these two SCC mixtures failed the workability tests.

$\mathrm{T}_{500}$ flow time for SCC was recorded to be $7.10 \mathrm{~s}$. This time was increased when 3D fibres were added in SCC. For SCC-S3D1, SCC-S3D2 and SCC-S3D3, $\mathrm{T}_{500}$ flow time was increased by $0.01 \mathrm{~s}, 0.07 \mathrm{~s}$ and $0.11 \mathrm{~s}$, respectively. For SCCL3D1, SCC-L3D2 and SCC-L3D3, this time was increased by $0.09 \mathrm{~s}, 0.57 \mathrm{~s}$ and $1.02 \mathrm{~s}$. 


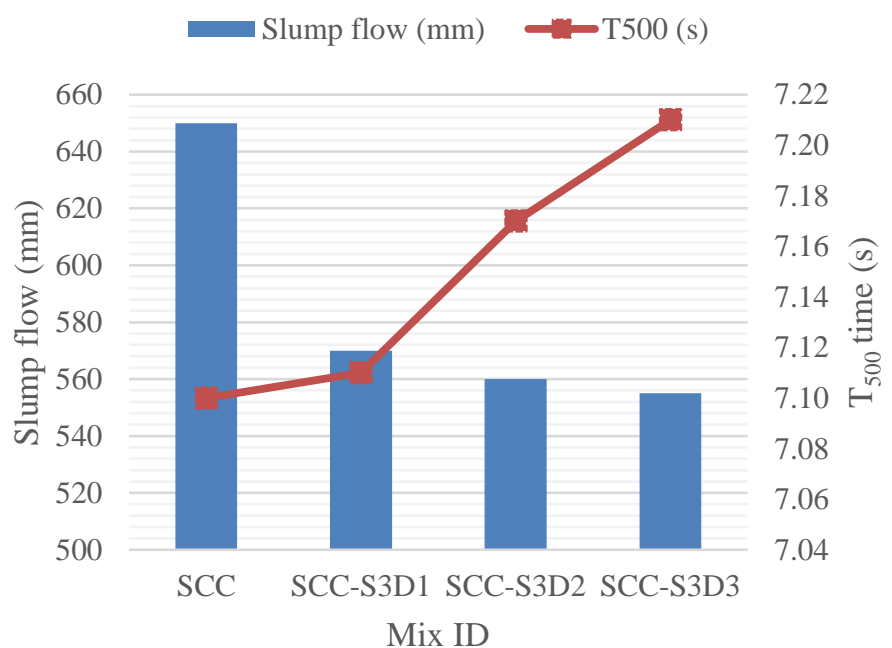

(a)

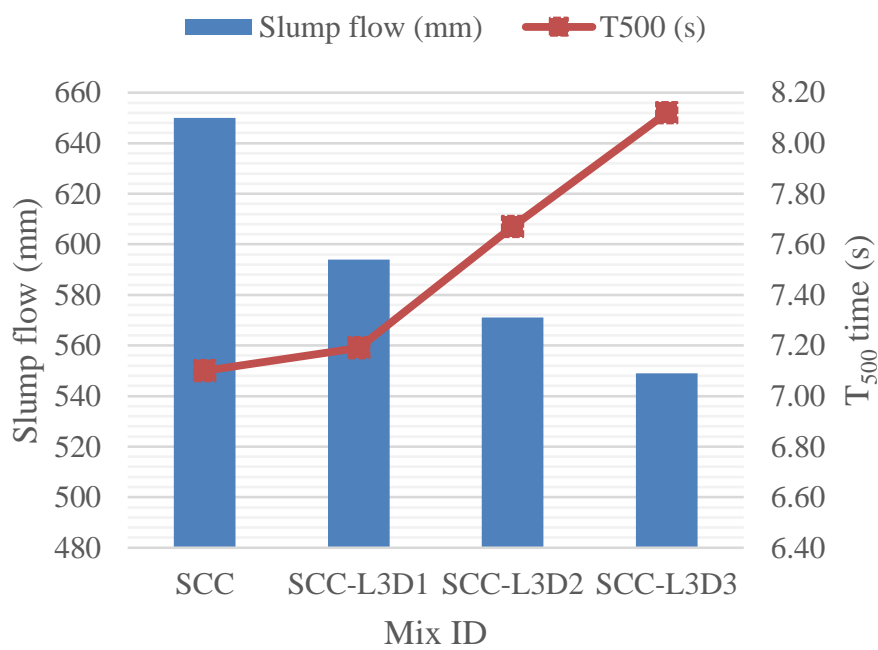

(b)

Fig. 4: Slump flow and $\mathrm{T}_{500}$ time for (a) SCC with S3D fibres (b) SCC with L3D fibres.

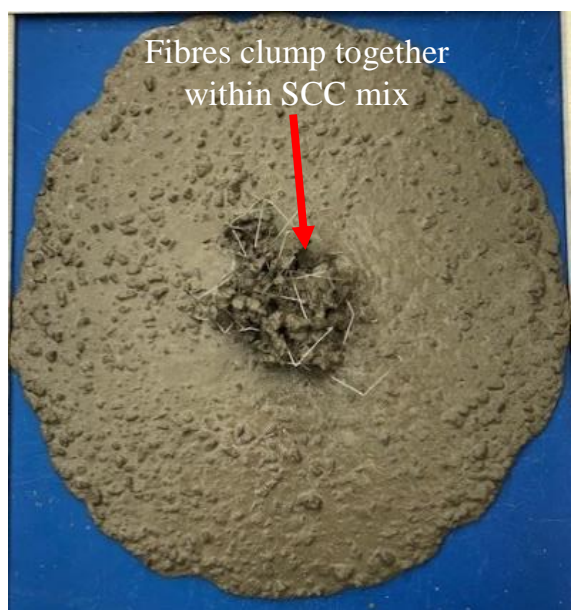

Fig. 5: Balling effect of fibres in the SCC mixtures.

\subsection{V-Funnel Time}

Results of V-funnel time for different SCC mixtures with 3D fibres are presented in Fig. 6. V-funnel time increased as the fibres were added in the mix. Increase in V-funnel time for SCC incorporating 1\%, 2\% and 3\% of S3D fibres were 3.16, 3.30 and $3.51 \mathrm{~s}$, respectively. Addition of $1 \%$ of L3D fibres increased the time of flow by $2.89 \mathrm{~s}$. However, when $2 \%$ and $3 \%$ of these fibres were added in the mix, the funnel outlet was blocked. Most of the SCC mixtures had a V-funnel flow time that was within the range of 9 to $25 \mathrm{~s}$ prescribed by EFNARC [7] and falls under the VF2 category, which is suitable to be used for tall and slender elements. Both SCC-L3D2 and SCC-L3D3, however, failed to meet these limits due to blockage of the V-funnel outlet during the test. 


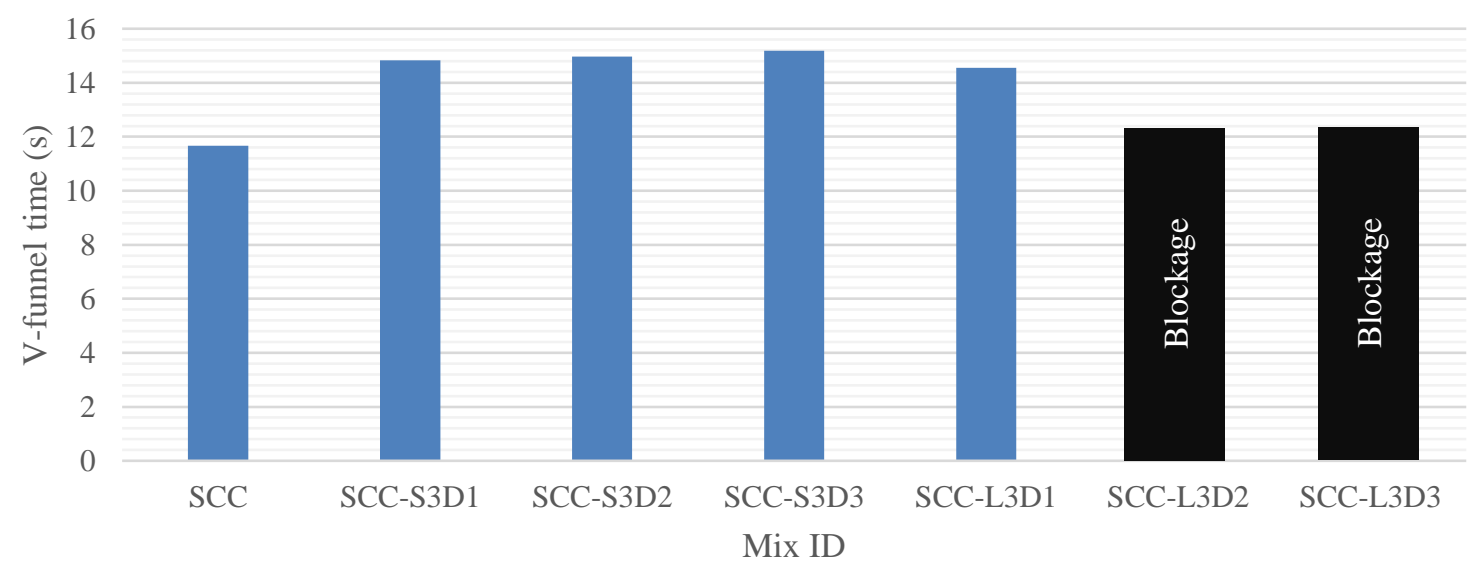

Fig. 6: V-funnel time for different SCC mixtures.

\subsection{J-Ring Test}

The ability of SCC to flow or its passing ability through obstruction and reinforcing bars was measured by using J-ring test [3]. The J-ring slump flow $\left(\mathrm{SF}_{\mathrm{J}}\right), \mathrm{T}_{500 \mathrm{~J}}$ flow time and difference in height or step height (PJ) between the levels of the SCC inside and outside of the ring at the end of its flow were determined. The maximum spread in J-ring varies in the range of 540 to $595 \mathrm{~mm}$ and the step height is between 15 and $103.5 \mathrm{~mm}$. The smaller step height value indicates better passing ability of the mix.

$\mathrm{T}_{500 \mathrm{~J}}$ flow time for SCC was recorded to be $7.72 \mathrm{~s}$. Similar to the results in the slump flow test in Section 3.1, $\mathrm{T}_{500 \mathrm{~J}}$ was increased when 3D fibres were added in SCC. For SCC-S3D1, SCC-S3D2 and SCC-S3D3, $\mathrm{T}_{500 \mathrm{~s}}$ flow time was increased by $0.42,0.47$ and $0.53 \mathrm{~s}$, respectively. For SCC-L3D1, SCC-L3D2 and SCC-L3D3, this time was increased by $0.11,0.32$ and $0.74 \mathrm{~s}$. In the case of SCC mixed with L3D fibres, none of the fibres were found outside the ring. As previously noted in section 3.1, the balling effect occurred during the test with the addition of $2 \%$ and 3\% of L3D in the SCC.

It is evident that the incorporation of S3D fibres into SCC gives better results than L3D fibres in terms of passing ability. Fig. 7 shows the J-ring slump flow diameter $\left(\mathrm{SF}_{\mathrm{J}}\right)$ and $\mathrm{T}_{500 \mathrm{~J}}$ time for different $\mathrm{SCC}$ mixtures.

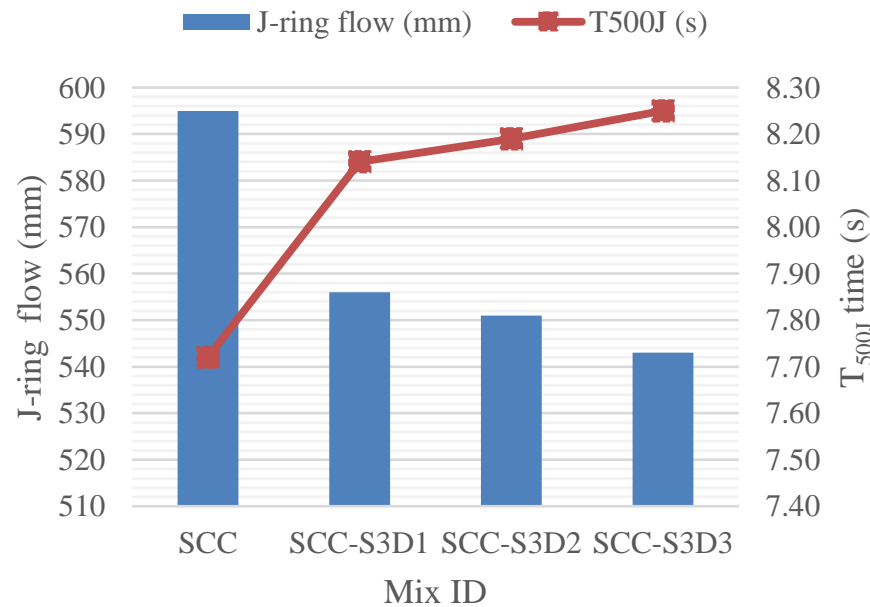

(a)

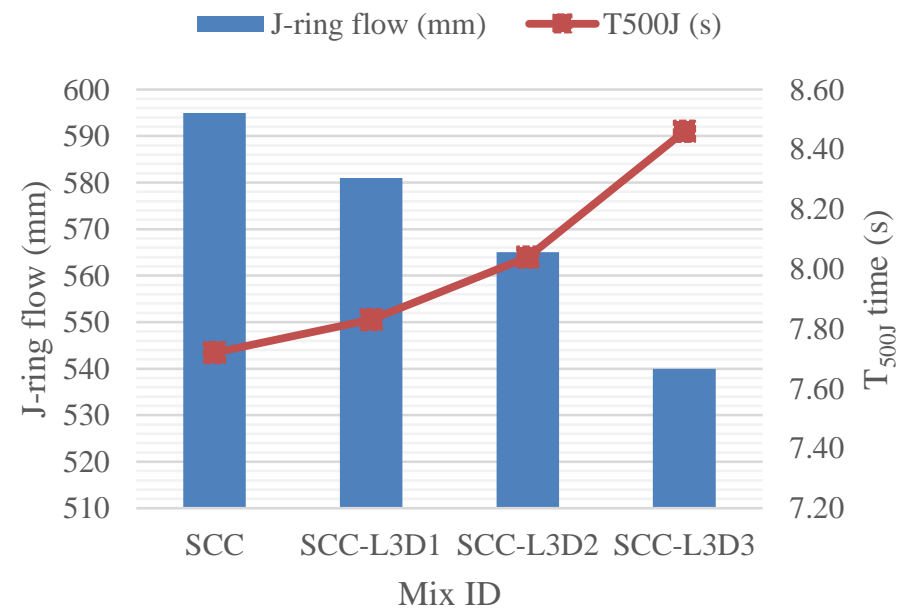

(b)

Fig. 7: J-ring flow and $\mathrm{T}_{500 \mathrm{~J}}$ time for (a) SCC with S3D fibres (b) SCC with L3D fibres. 


\subsection{Segregation Resistance}

The sieve segregation resistance test was carried out to investigate the resistance of SCC to segregation. According EFNARC [7], the limiting value for sieve segregation resistance test is less than $20 \%$ for SR 1 and $15 \%$ for SR2. The of segregation percentage for all SCC mixtures are shown in Table 5. Decrease in the percentage of segregation for SCC incorporating $1 \%, 2 \%$ and $3 \%$ of S3D fibres were $0.3 \%, 0.7 \%$ and $1.1 \%$, respectively. Addition of $1 \%, 2 \%$ and $3 \%$ of fibres increased the percentage of segregation by $1.1 \%, 0.7 \%$ and $0.2 \%$. In this present study, all the SCC mixes achieved a segregation ratio of less than 5\%, which may be classified as class SR2 and is suitable to be used for tall vertical applications. The lower percentage of segregation indicates a higher resistance to segregation.

As shown in Table 5, the visual stability index (VSI) values of the SCC mixtures were in the range of 0 to 1, according to ASTM C1611 [12]. SCC, SCC-S3D1, SCC-S3D2 and SCC-L3D1 all had the same VSI value of 0 because there was no evidence of segregation or bleeding. The VSI value for SCC-S3D3, SCC-L3D2 and SCC-L3D3 was rated 1 with slight bleeding observed as a sheen on the concrete mass. As a result of high cement content and smaller aggregate sizes in the SCC mix, high segregation resistance results can be achieved [5].

\section{Conclusion}

An experimental investigation was performed to study the rheological properties of SCC with two different sizes of 3D fibres; those with a perimeter of $115 \mathrm{~mm}$ (S3D) and those with a perimeter of $220 \mathrm{~mm}$ (L3D), each with varying fibre volume fractions $(1 \%, 2 \%$ and $3 \%$ by mass of cement). The results obtained in this study can be summarised as follows:

- Addition of 3D fibres decreases the workability of the SCC; especially when 2\% and 3\% fibre volume fractions of L3D were added to the mixture, the clumping of fibres or "balling effect" occurs, which have an adverse effect on the workability of SCC. The results revealed that the passing ability of SCC reduces when 3D fibres were added to the SCC, and hence, SCC with high fibre content cannot pass easily through the rebars.

- The workability of SCC mixtures with S3D is better than of those with L3D. The workability properties of SCC mixtures with $1 \%, 2 \%$ and $3 \%$ of S3D fibres and with $1 \%$ of L3D fibres were within the limits prescribed by EFNARC [7]. The SCC mixtures with $2 \%$ and 3\% of L3D fibres, however, failed to meet these limits in terms of filling ability and passing ability.

\section{Acknowledgements}

This research project forms part of the Intensive Industrial Innovation Programme (IIIP) funded by the European Regional Development Fund. Special thanks of the authors are extended to Lynx Precast Ltd for providing materials resources, financial and technical support of this research study. Cooperations of strong floor laboratory technicians at Northumbria University are also appreciated.

\section{References}

[1] B. H. Nagaratnam, M. E. Rahman, A. K. Mirasa, and M. A. Mannan, "Workability of self-compacting concrete using blended waste materials," in Advanced Materials Research, vol. 1043, pp. 273-277. Trans Tech Publications, 2014.

[2] B. H. Nagaratnam, M. E. Rahman, and M. A. Mannan, "A Study on Hardened State Properties of SCC using Fly Ash and Blended Fine Aggregate," in Advanced Materials Research, vol. 587, pp. 21-25. Trans Tech Publications, 2012.

[3] EFNARC, "The European guidelines for self-compacting concrete specification, production and use," 2005.

[4] S. Ahmad, and A. Umar, "Rheological and mechanical properties of self-compacting concrete with glass and polyvinyl alcohol fibres," Journal of Building Engineering, vol. 17, pp. 65-74, 2018.

[5] B. H. Nagaratnam, M. A. Mannan, M. E. Rahman, A. K. Mirasa, A. Richardson, and O. Nabinejad, "Strength and microstructural characteristics of palm oil fuel ash and fly ash as binary and ternary blends in Self-Compacting concrete," Construction and Building Materials, vol. 202, pp. 103-120, 2019.

[6] H. Okamura, and M. Ouchi, "Self-compacting concrete," Journal of Advanced Concrete Technology, vol. 1, no. 1, pp. $5-15,2003$. 
[7] Q. Song, R. Yu, Z. Shui, X. Wang, S. Rao, Z. Lin, and Z. Wang, "Key parameters in optimizing fibres orientation and distribution for Ultra-High Performance Fibre Reinforced Concrete (UHPFRC)," Construction and Building Materials, vol. 188, pp. 17-27, 2018.

[8] S. Yehia, A. Douba, O. Abdullahi, and S. Farrag, "Mechanical and durability evaluation of fiber-reinforced selfcompacting concrete," Construction and Building Materials, vol. 121, pp. 120-133, 2016.

[9] K. Khayat, G. Schutter, "Mechanical Properties of Self-Compacting Concrete," RILEM State-of-the-Art Reports 14, pp. 161, 2014.

[10] BS 197-1, "Cement. Composition, specifications and conformity criteria for common cements," British Standard Institute, London, UK, 2011.

[11] A. Richardson and M. Heather, "Improving the performance of concrete using 3D fibres," in Procedia Engineering, vol. 51, pp. 101-109, 2013.

[12] EFNARC, "Specification and guidelines for self-compacting concrete," 2002.

[13] ASTM C1611/C1611M-18, Standard Test Method for Slump Flow of Self-Consolidating Concrete, ASTM International, West Conshohocken, PA, 2018.

[14] A. Pulgur, L. Divakar, R.C. Gowda, and B. Nagesh, "Influence of Steel Fibres on Mechanical Properties of Geopolymer Concrete," in Green Buildings and Sustainable Engineering, pp. 423-430. Springer, Singapore, 2019. 